who described experiments on the high-frequency conductivity of metals at low temperatures. It is well known that the classical theory, supported by measurements at moderately high frequencies, indicates that the resistivity of a conductor as determined by the skin effect should be inversely proportional to the square root of the bulk conductivity. Experiments made at a frequency of $1,200 \mathrm{Mc}$./s. have shown, however, that while this is true at room temperature, the great increase in conductivity due to cooling pure metals to very low temperatures is not accompanied by a corresponding decrease of surface resistivity. The explanation of this effect is that the free paths of the conduction electrons at low temperatures may exceed the classical value of the skin depth by as much as a factor of 100 under the conditions of the experiments. Thus it is no longer permissible to assume the validity of Ohm's law, since only a small proportion of the relevant electrons contribute to the surface con. ductivity. It is clear that we have here a quantitative radio technique for exploring the free paths of electrons, and investigations were referred to in which the method is being applied to the study of the surface characteristics of pure metals.

In the course of the discussion, Dr. R. A. Smith very aptly referred to the interesting fact that physicists, who had so ably assisted the radio investigators in the development and exploitation of radar and communications during the War, have now taken back into their own research laboratories some of the problems exposed by the radio engineers. The development of the higher frequency radio techniques in the past few years has clearly provided powerful research tools for studying the general physical constitution of matter.

R. L. SMITH-Rose

\section{PROBLEMS OF TIDAL BIOLOGY}

$I^{N}$ N a letter published in Nature in $1944(154,300)$ it was pointed out by Prof. T. A. Stephenson, of University College, Aberystwyth (in continuation of an argument initiated by Prof. F. E. Fritsch, Nature, $154,144 ; 1944)$, that future investigation of intertidal biology in Great Britain demanded : $(a)$ further work on the British coasts between tide-marks; (b) further work on the continental shelf of the British region below tide-marks ; and (c) an attempt to make a preliminary world statement, based on a carefully selected series of surveys made by the same workers.

Since 1944 progress has been made towards the realization of all these objectives, but the present article is concermed particularly with the third one. Prof. Stephenson has now undertaken to write a monograph on plant- and animal-life between tidemarks throughout the world, and the expedition described below was a step in that direction. The monograph is intended to supplement the well-known works of Ekman ("Tiergeographie des Meeres", 1935) and of Sverdrup, Johnson and Fleming ("The Oceans", 1942). These volumes both provide worldwide pictures of certain aspects of marine life, but neither devotes particular attention to the intertidal region; nor is there any general work which attempts to do this. In the task which he has under. taken, Prof. Stephenson will have behind him thirty years experience of ecological work between tidemarks carried out in Australia, South and East
Africa, Mauritius and Great Britain, much of which is embodied in a series of admirable papers. The shores of 'North America have now been added to the regions studied by him. In much of this work, of a type which could not be conducted unaided, Prof. Stephenson has been assisted by collaborators, and throughout Mrs. Stephenson has acted as his technical assistant.

Between December 1946 and January 1948, Prof. and Mrs. Stephenson made a thirteen months visit to the United States and Canada to collect new material for their monograph. It has been recognized throughout that, while nobody can expect to visit all the coasts of the world in this connexion, there is a certain amount of uniformity between one coast and another within the same temperature limits. There is thus reason to expect that a judiciously chosen series of samples will provide a basis for a general statement which, if only a first approximation, will form a foundation for later work. It so happens that most of the samples needed to complete Prof. and Mrs. Stephenson's earlier experience are to be found in North America. On this ground their visit was supported either financially or by the provision of facilities, or both, by a number of institutions in Great Britain and America.

While the intertidal ecology of the North American coasts is much better known than that of South America, it has been investigated less than might be supposed. There is an extensive literature dealing with the systematics of intertidal plants and animals, and a very considerable amount which describes the biology of particular species. Contributions reviewing the shore ecology as a whole are much fewer, and where they exist, may deal primarily with animals (for example, Hewatt ${ }^{1}$ ) or with plants (for example, Doty $^{2}$ ) and rarely cover wide areas, except in occasional works such as that of Ricketts and Calvin ${ }^{3}$, and the paper by Doty already mentioned. There are vast stretches of the coast which remain almost unknown from an ecological point of view. The places visited during the present work were chosen, so far as possible, in areas where the general shore ecology has not been described. The summary which follows is derived from a privately printed report prepared for submission to the institutions which supported the work.

The time spent in America extended from January 1, 1947, to January 25, 1948. During this period a distance of some 15,000 miles was covered, mainly by motor-car, and shore-work was carried out first on the Atlantic coast-among the Florida Keys, at Marineland in North Florida, at Charleston in South Carolina and at Beaufort in North Carolina. After crossing the continent it was continued on the Pacific coast at Nanaimo in British Columbia, and afterwards at Pacific Grove and La Jolla in California. This schedule permitted a stay of approximately two months at each of the main centres.

The amount of information collected was considerable, and it will be some time before it can be worked up for detailed publication. Meanwhile the following note will indicate the nature of the results. The work falls roughly under three headings: $(a)$ broad geographical aspects; $(b)$ questions of vertical and horizontal distribution within small areas; and $(c)$ the causes of the facts observed under $(a)$ and $(b)$.

The Florida Keys represent a tropical region with an abnormally scanty intertidal population; scanty, that is to say, in total bulk of organic material regarded as a crop, not in number of species repre. 
sented. The latter is considerable. The environmental features with which this poverty is connected appear to be produced by a peculiarly shallow, very heavily sedimented sea, with a low concentration of nutrient salts, operating in a tropical region with a rather small tidal range, on a clinker-like substratum formed from dead coral. This situation will be described for the first time, and it is hoped that a comparison of so unusual a tropical area with more ordinary ones will yield information about the underlying reasons for the differences.

The coasts of northern Florida, together with those of North and South Carolina, present an entirely different picture. It is hoped to show that between Cape Hatteras and Cape Canaveral there lies a region inhabited by a warm-temperate tidal biota with distinctive features of its own. The coast here consists primarily of sand, mud and gravel, outcrops of material harder than peat being exceptional; but the lack of hard substrata is made up for, to some extent, by the existence of rough rocky breakwaters essentially similar to reefs of natural rock. Information has been obtained relating to the reaction of a warm-temperate population of seaweeds and animals to the presence of small areas of hard bottom lost among vast tracts of sand, and it is expected that this will prove to be useful material for a general discussion of the problems of intertidal life.

On the Pacific coast, the areas visited provide the following special features. At Nanaimo in British Columbia there flourishes a superb example of a rich, fully marine fauna, in a region of quiet creeks with reduced wave-action, in a low range of salinity $(23-28 \%$ \% $)$ It is remarkable in itself that so large a population of stenohaline animals such as starfish and anemones should flourish in water of such low salinity; but the district offers also, in the form of Brandon Island, a small island with a gradual, sunny, southward slope and a precipitous, shady, northern cliff, a perfect demonstration of the effect on plant and animal distribution of the contrast between these two combinations of conditions. Other reefs and islands in the district supplement what Brandon Island supplies, and also offer contrasts. Around the Monterey Peninsula and Point Lobos in California, on the other hand, there is found an example of a more southerm version of a population not unlike that of Nanaimo, but exposed (on the more wave-beaten promontories) to maximal oceanic wave-action. In spite of the powerful wave-action, however, the very rugged and irregular nature of the coast provides so many degrees of exposure to, and shelter from, wave-action in small areas that the effect of these differences on a rich marine population in an area of normal salinity can be studied to advantage. Lastly, in the neighbourhood of La Jolla, neur the boundary between Mexico and California, another very different picture is encountered. The wave action, while considerable and oceanic, is moderate compared with that of the Monterey region; and the shore biota is of a warm-temperate type, distinctly different ecologically from that of the more northern stations. The rock along the shore, moreover, provides a remarkable demonstration of the effect of different degrees of hardness on the species which can colonize it. The most prevalent rock is so soft that it has specific unusual effects on common organisms such as barnacles and encrusting Corallinaceæ; and these effects can be checked by comparison with local areas in which the rock is harder, in varying degrees, than the average, and which show clearly what happens on hard rock as compared with soft in the same district.

Throughout the work special attention has been paid to the zonation of plants and animals between tide-marks, and the relationship between zones and tide-levels will figure largely in the results. During their previous work in South Africa (see Nature, 143, 503 ; 1939 ; and 156, 27; 1945) Prof. and Mrs. Stephenson developed the idea that the shore zonation found there is based on a plan of universal application. They were able to test this idea later in Great Britain, Mauritius and East Africa, but during 1947-48 tested it much more widely on a variety of American shores. So far it has stood this examination very well, but there is much work to be done before the detailed application can be made.

The regional peculiarities of different parts of the world reveal themselves in many ways. This is shown particularly well by the distribution of limpets, which is one of the subjects covered in this work. While limpets of some kind are peculiarly characteristic of the intertidal regions of the world, the genera to which they belong show a markedly regional occurrence. Thus, in some areas the leading limpet genus is Patella; in others Acmoea; and on many of the warmer shores the pulmonate Siphonaria. An interesting point brought out by the present study is that the Carolina coasts visited are most exceptional in that, to all appearance, they have no limpets at all on open rock surfaces.

The prime object of the work here summarized was not the amassing of facts as such but their comparative study with the view of elucidating the underlying fundamental principles which are respon. sible for the surface appearances described. These principles cannot, however, be formulated until a full examination of the facts has been made. In the course of this expedition Prof. and Mrs. Stephenson have added greatly to their already unique experience in the study of shore ecology. It is most sincerely to be hoped that nothing will prevent, indeed that circumstances will conspire to further, the production of the monograph to the completion of which on the broadest possible basis their labours are directed.

$$
\text { C. M. Yonge }
$$

${ }^{1}$ Hewatt, W. G., Amer. Midland Naturalist, 18, 161 (1937).

'Doty, M. S., Ecology, 27, 315 (1946).

${ }^{3}$ Ricketts, E. F., and Calvin, J. "Between Pacific Tides" (Stanford Univ. Press and Oxford Univ. Press, 1939).

\section{OBITUARIES}

Prof. G. H. Hardy, F.R.S.

Godfrey HaROLD HaRdy, who died at Cambridge on December 1, 1947, was the creator of the English school of mathematical analysis and had been for more than a quarter of a century the leader of pure mathematicians in Great Britain. He was born on February 7, 1877, the son of Isaac Hardy, who was bursar and art master at Cranleigh School. He went to Winchester and, in 1896, as a scholar to Trinity College, Cambridge. He was fourth wrangler in 1898 and was placed in the first division of the first class in Part II of the Mathematical Tripos in 1900. He was elected a fellow of Trinity in 1900 and (together with Jeans) gained a Smith's Prize in 1901.

At the turn of the century, pure mathematics in Britain was at a low ebb. Since the days of Newton, 